\title{
Estimation of urban mixed layer height in Zanjan using LIDAR observations and numerical modeling
}

\author{
A A Bidokhti ${ }^{1, *}, \mathrm{M} \mathrm{Khoshima}^{1}, \mathrm{~S} \mathrm{Sabetghadam}^{1}$ and H M Khalesifard ${ }^{2}$ \\ ${ }^{1}$ Institute of Geophysics, University of Tehran, Tehran, P. O. Box: 14155-6466, Iran. \\ ${ }^{2}$ Institute of Advanced Studies in Basic Sciences, Zanjan, Iran. \\ *e-mail: bidokhti@ut.ac.ir
}

\begin{abstract}
Air pollution predictions often require the height of atmospheric mixed layer in time especially in big cities. Here, the variation of the height of this layer is estimated from direct measurements and also from a numerical forecast model with a high resolution boundary layer scheme. The height of the daytime mixed layer for the city of Zanjan $\left(48.5^{\circ} \mathrm{N}, 36.7^{\circ} \mathrm{E}, 1700 \mathrm{~m}\right.$ above sea level) is measured using a LIDAR $(532 \mathrm{~nm})$ system, which works based on aerosols scattering of laser light. The mixed layer height $\left(z_{i}\right)$ for Zanjan city, well above mean sea level compared to other major cities in the world, is found to be between $1.4 \mathrm{~km}$ typically in spring and $2.2 \mathrm{~km}$ in summer, for synoptic calm conditions. Also, the MM5 forecast model with a proper boundary layer scheme (MRF) is used to estimate $z_{i}$ which shows rather good agreement with direct observations using the LIDAR system. The entrainment zone of the mixed layer was also found to undergo some occasional temporal growth that may be attributed to shear instability that led to more mixed layer growth.
\end{abstract}

\section{Introduction}

Processes of the planetary boundary layer are of extreme importance for both large-scale atmospheric dynamics and for a large number of meteorological applications such as air pollution studies. Observational study of the atmospheric layers, especially at low altitude, is very important because of the effects of aerosols, water vapor and pollutants on radiation budget of the atmosphere. The lowest part of the atmosphere namely the atmospheric boundary layer (ABL) has a thickness which is quite variable in time and space over land, ranging from hundreds of meters to a few kilometers (Stull 1988). However, over the ocean as the sea surface temperature changes little over a diurnal cycle, boundary layer height varies little over the ocean. Over land surfaces, the boundary layer has a well-defined structure that evolves with the diurnal cycle. In a diurnal cycle, after sunrise the atmospheric boundary layer known as mixed layer (ML) grows and in the afternoon it subsides as often seen in remote sensing observations (e.g., figure 1). This has an important implication on the air pollution over big cities or in industrial areas over the land.

Different experimental techniques can be used to monitor the height within the lower troposphere. Some techniques are based on direct measurements of atmospheric parameters, using meteorological towers, radio-sounding or tethered balloons; others are based on remote sensing measurements, performed with SODAR (sound detection and ranging), RADAR, or LIDAR (light detection and ranging) techniques (Tomasi and Perrone 2005). Remote sensing techniques have the advantages of providing high temporal and spatial resolution information about mixed layer height (MLH). In addition, remote sensing methods can well represent a regional average mixed layer height by smoothing the results over a span of time.

LIDAR is a laser application method for remote sensing which has been used for more than two decades and it has provided the first opportunity

Keywords. Urban area; mixed layer height; LIDAR; entrainment zone; mesoscale numerical model (MM5). 


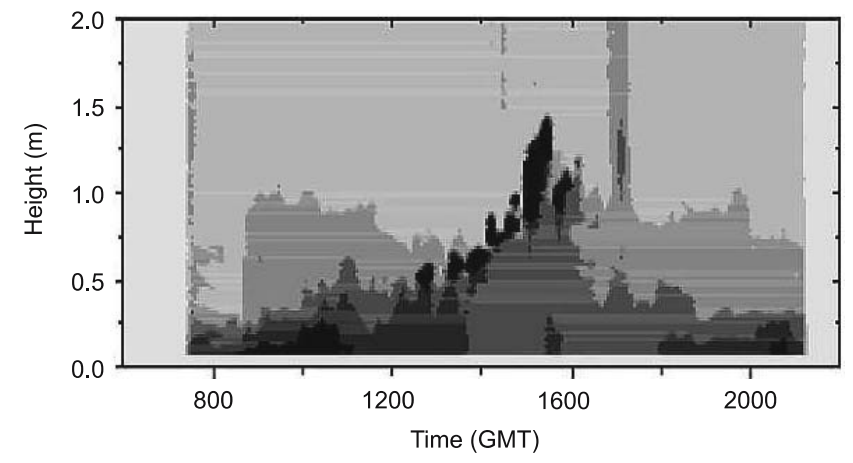

Figure 1. Growth of the mixed layer height based on the LIDAR signal (Flamant and Flamant 1997), the residual layer is also observed with the entrainment zone being highly variable with time.

to observe those processes evolving in real time in the atmosphere. Active remote sensing instrument such as LIDARs usually use aerosols as tracers of the ABL properties. The backscattered optical power, measured by LIDAR is proportional to the aerosol content in the atmosphere. The aerosol is also more abundant in the ABL apart from clouds with high level of hydro particles. LIDARs operating in the UV and visible spectral regions are sensitive to the elastic backscattering from molecules and aerosols. However, in the interface region between free atmosphere and boundary layer (or in between cloud layers), the vertical variation of the molecule concentration is small, whereas the vertical variation of aerosol concentration is large. Therefore, LIDARs can be used to follow the time evolution of atmospheric aerosol layers and can also be well suited for long-term monitoring of atmospheric boundary layer (ABL) height (with more aerosols) and cloud layers. It is also used to provide vertical profiles of several of the key parameters such as some of the chemical constituents of the atmosphere, the relative humidity, horizontal wind speed, vertical velocity, potential temperature, etc.

Daytime mixed layer, especially in urban areas, has much higher concentrations of water vapor and aerosols than that of free atmosphere that can cause sharp LIDAR signal change around the top of this layer. Thus, LIDAR can be used to monitor the temporal and spatial variations of mixed layer height over urban areas (Boers et al 1984; Melfi et al 1985). As the mixed layer is moister and has more aerosol content, causing more scattering of laser light than that of the free atmosphere, it can be used to detect the top of the boundary layer easily (Kunkel et al 1977; Flamant and Pelon 1996; Stull and Eloranta 1984). A number of studies have focused on the comparison between LIDAR measurements and other conventional measurements, and in general, the LIDAR technique is considered to be suitable for estimating the mixed layer height (Marsik et al 1992). LIDAR systems are also used to examine the structure and variability of the top boundary layer and to derive the entrainment zone depth (Boers et al 1984; Melfi et al 1985; Nelson et al 1989; Cohn and Angevine 2000). The data generated by LIDAR systems are substantial and hence, automated processing methods are essential for the full use of all the available information.

Also important are the surface layer properties, entrainment processes in the top of mixed layer and the main boundary layer turbulent flux profiles. The former can be easily measured directly, while the latter are not as accessible. Simple parameterizations of entrainment heat flux are often based on the entrainment zone thickness (Driedonks and Tennekes 1984). Knowledge of mixed layer height and entrainment zone thickness is thus important for the understanding of the atmospheric boundary layer structure. They can be determined by the measurement of profiles of a variety of atmospheric properties of which potential temperature being the most common. Nowadays using remote sensing methods as LIDAR can be very handy in such measurements.

In addition to field measurements of the ABL, another important area of research involves numerical simulations of boundary-layer structure and its evolution. This allows experimentation under carefully controlled conditions. Many numerical models have already been developed for a wide range of applications with different degrees of sophistication. Today, numerical models are capable of simulating a number of different aspects of atmospheric motions that can be used for weather forecasts and other meteorological applications. For example, MM5 (a meso-scale numerical weather forecast model) model is usually used as one of the meteorological preprocessors for air quality models (Seaman 2000; Hogrefe et al 2001). Large eddy simulation of ABL has also become popular in more detailed study of turbulence in this layer (e.g., Mason 1989).

In this paper, the depth of the daytime mixed layer for the city of Zanjan $\left(48.5^{\circ} \mathrm{N}, 36.7^{\circ} \mathrm{E}, 1700 \mathrm{~m}\right.$ above sea level, ASL) has been studied using a home made LIDAR $(532 \mathrm{~nm})$ system. Also the MM5 forecast model with a proper boundary layer scheme (MRF) is used to estimate atmospheric boundary layer height for comparison, as there are not much upper level meteorological data in this region.

\section{Description of the LIDAR site}

The boundary layer height was estimated by a 532-nm elastic backscatter LIDAR located at the 


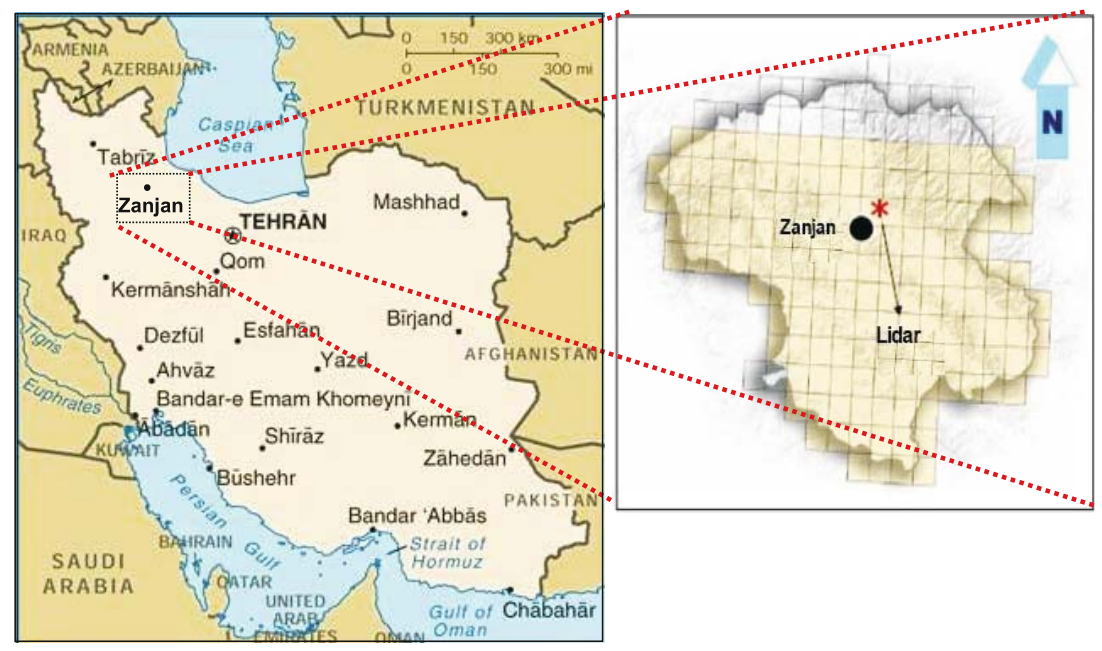

Figure 2. An overall view of the area and the location of LIDAR $\left(48.5^{\circ} \mathrm{N}, 36.7^{\circ} \mathrm{E}, 1700 \mathrm{~m} \mathrm{ASL}\right)$.

Institute for Advanced Studies in Basic Sciences of Zanjan $\left(48.5^{\circ} \mathrm{N}, 36.7^{\circ} \mathrm{E}\right)$. Zanjan city is $1700 \mathrm{~m}$ ASL and it is one of the highest elevated large cities in Iran (see figure 2); hence the LIDAR observation site is at about $1700 \mathrm{~m}$ ASL. The site is located in a semi-arid area in the north of Iran that is surrounded by mountains; it also lies on the south of the Alborz Mountain range; and on the northern terrain of these mountains lies the Caspian Sea.

Zanjan has a rather Mediterranean climate, characterized by cold snowy weather in the mountains and a moderate climate in the plains in wintertime with an average minimum temperature of $-19.5^{\circ} \mathrm{C}$. In the summer, weather is warm and dry with an average maximum temperature of about $27^{\circ} \mathrm{C}$. The average annual rainfall in the first month of spring stands at $72 \mathrm{~mm}$, while in the second month of summer, it slips to a mere $3.6 \mathrm{~mm}$. The humidity in these periods typically stands at an average of $74 \%$ in the morning and $43 \%$ at noon. All these values are derived from the meteorological records of the last 30 years.

The ABL measurements were undertaken continuously for two periods in two seasons, spring and summer. In the set-up of our in-house built LIDAR, two harmonic pulses of an Nd-YAG laser (wavelengths, $\lambda=532 \mathrm{~nm}, 1064 \mathrm{~nm}$ ) with pulse duration of $5 \mathrm{~ns}, 30 \mathrm{~mJ} /$ pulse of energy for $532 \mathrm{~nm}$ and $50 \mathrm{~mJ} /$ pulse for $1064 \mathrm{~nm}$ and repetition rate of 1 to $20 \mathrm{~Hz}$ depended on different channels, were beamed to the zenith point (here we chose $1 \mathrm{~Hz}$ for repetition rate). The backscattered signals were gathered by a $14^{\prime \prime}$ Schmidt-Cassegrain telescope. A photomultiplier with a wide spectral response, which is placed in the telescope focal plane, sends the backscattered signals to a digital oscilloscope (Tektronix $1 \mathrm{GHz}$, TDS 680B). Each recorded signal on the oscilloscope is transferred to a PC
Table 1. The LIDAR specifications.

\begin{tabular}{ll}
\hline Transmitter & \\
Wavelength & $532 \mathrm{~nm}, 1064 \mathrm{~nm}$ \\
Output energy & $40 \mathrm{~mJ}$ \\
Pulse duration & $5 \mathrm{~ns}$ \\
Repetition rate & $\mathrm{Up} \mathrm{to} 20 \mathrm{~Hz}$ \\
Receiver & \\
Telescope & Newtonian \\
Main mirror diameter & $25 \mathrm{~cm}$ \\
Equivalent focal length & $1 \mathrm{~m}$ \\
Optical band width & $1 \mathrm{~nm}$ \\
Photo detector & $532 \mathrm{~nm}, 1064 \mathrm{~nm}$ \\
Data acquisition and processing \\
Time resolution & $1 \mathrm{microsec}$ \\
Spatial resolution & $50 \mathrm{~m}$ \\
\hline
\end{tabular}

computer through a GPIB interface. Specifications of the LIDAR are summarized in table 1.

The LIDAR signal is given by:

$$
S(r)=\frac{\left[K\left(B_{a}(r)+B_{m}(r)\right) T(r)\right]}{r^{2}}+S_{0}
$$

where $r$ is the distance from the laser to target, $K$ is the system constant, $B_{a}$ and $B_{m}$ are the backscatter coefficients by aerosol particles and air molecules respectively, $T(r)$ is atmospheric transmission and $S_{0}$ is the background signal. In this system a narrow band interference filter is utilized to reduce the background signal, $S_{0}$ substantially during the daytime. The overlap or dead zone for this system is below about $100 \mathrm{~m}$ as it uses a high performance beam expander, and the spatial resolution is $50 \mathrm{~m}$. 


\section{Altitude $(\mathrm{km})$}

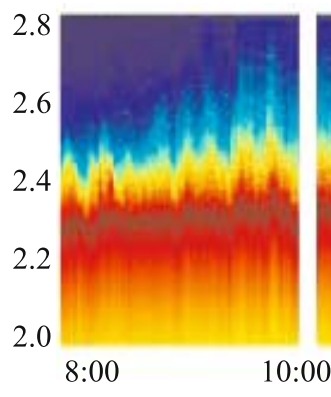

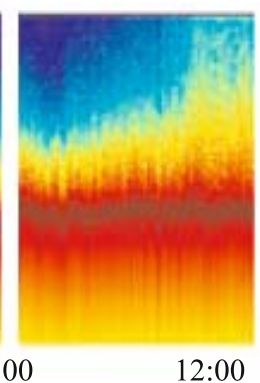

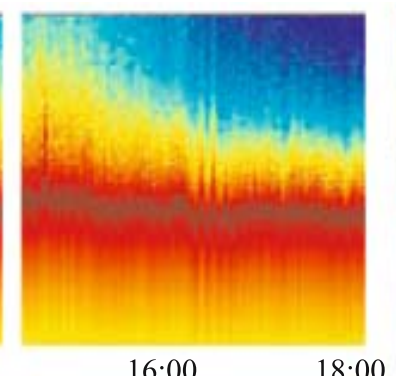

16:00

18:00

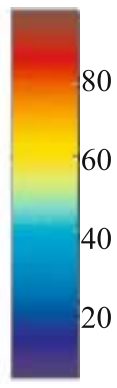

20

Local time (hr)

Figure 3. Diurnal variation of mixed layer height in Zanjan for 14 May 2006, in terms of aerosol backscattered light (the color chart is an arbitrary scale unit proportional to backscattered light). Note that the LIDAR is at about $1700 \mathrm{~m}$ ASL.

The LIDAR signal for each 60 consecutive returns is averaged that formed each LIDAR record in the data. The LIDAR signal $S(r) r^{2}$ is plotted according to a color scale chart and altitude $r$ as a function time, where the altitude with respect to ground level is $r$ and $S(r)$ is the backscattered signal (for further details of this system, see Khalesifard et al 2004).

LIDAR data which contain the information of the vertical profile of aerosol distribution in terms of time series are used to extract estimates of mixed layer growth and the entrainment zone of the atmospheric boundary layer. In the vertical profiles of aerosol concentration of LIDAR signal, top of the boundary layer and boundaries of the clouds in the free atmosphere (if present) are particularly marked. This is because the backscatter signals from the aerosol sharp gradients of these layers are strong. Boundary layer has usually much more aerosols than the free atmosphere above; hence the boundary between the two in LIDAR backscattered signal is usually marked.

\section{Results and discussion}

\subsection{LIDAR observations}

Measurements were undertaken for about $325 \mathrm{~h}$, especially from morning till afternoon, in two 10-day periods during two seasons; spring and summer. During the LIDAR observations, 45 time series (at least from about $2 \mathrm{~h}$ before the sunrise to $2 \mathrm{~h}$ after sunset) were recorded from which 14 of them were discarded because of the presence of fog, cloudiness, and rain that obscured the measurements. Therefore, days with no synoptic forcing, usually under high pressure and stable atmospheric conditions are considered. The vertical range of the LIDAR is typically $15,000 \mathrm{~m}$ of which we focus on the first $3000 \mathrm{~m}$. The daily mixed layer height was estimated via the LIDAR z-t images. We estimated the height of the mixed layer, $z_{i}$ from the LIDAR backscattered data directly that usually show the boundary with strong aerosol concentration gradient (negative $\partial S(r) r^{2} / \partial r$ ) very vividly. We have not used any algorithm for this derivation, and the approximate error in the estimation of the height of the maximum of the backscatter is about $10 \%$ typically (Rocadenbosch 2003). It should be mentioned that in the early morning we may have a residual layer (adiabatic mixed layer from the previous day) above the eroding stable layer above the shallow developing ML that may give two LIDAR signals. Usually the lower one should be used. However, this is not possible always and MLH estimation as opposed to boundary layer height, in the early mornings may be associated with more error.

\subsubsection{Daily growth of the mixed layer height}

The diurnal cycle of mixed layer is defined by the growth of mixed layer height after sunrise reaching a maximum value at about 13:00 of local time in spring and 12:30 local time in the summer for Zanjan, and then in the afternoon it subsides. For example, figure 3 shows a typical trend of LIDAR (for $532 \mathrm{~nm}$ ) z-t image of this variation on 14 May 2006 (a typical spring day) for that the synoptic situation is characterized by a heat low pressure system located in the Eastern Europe and a high pressure system in the north of the Caspian Sea (figure 4).

Figure 5 shows the MLH for three typical days that we measured by this LIDAR. For a spring day (10 May) the growth is initially slow and increases in time with typical rate of $100 \mathrm{~m} / \mathrm{h}$ and levels off near noon for which it reaches its maximum of about $1400 \mathrm{~m}$. Figure 5 also shows the growth 


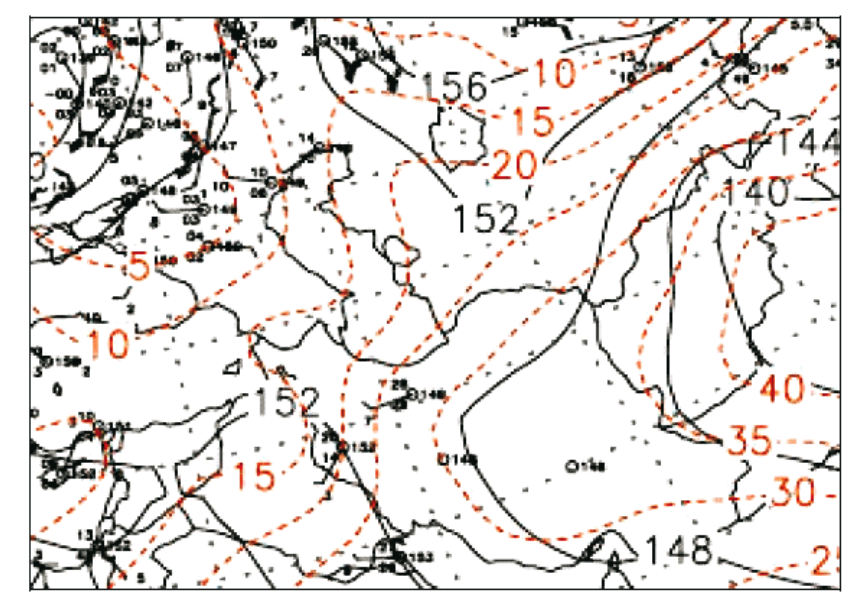

Figure 4. Synoptic situation on 14 May 2006 of $850 \mathrm{hPa}$ surface. Solid lines represent height and broken curves show isotherms, while the dotted lines are latitudes and longitudes.

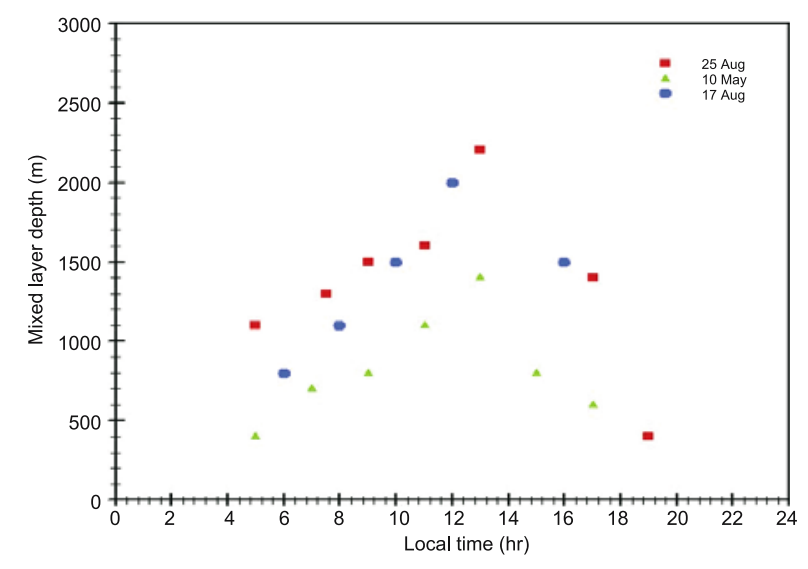

Figure 5. Boundary layer height during 10 May, 17 and 25 August 2006 using LIDAR observations.

of boundary layer height during 25 August 2006 (a typical summer day) for which the synoptic situation is characterized by a high pressure system located in the north of Iran which yields a stable weather condition. The boundary layer height increases with a rate of $200 \mathrm{~m} / \mathrm{h}$, and it achieves its maximum of $2200 \mathrm{~m}$ at about 13:00 local time; then in the afternoon it subsides, and at about 19:00 it reaches near $200 \mathrm{~m}$. During 17 August 2006 after sunrise mixing height grows with a rate of $230 \mathrm{~m} / \mathrm{h}$ and reaches a maximum height of about $2000 \mathrm{~m}$ at noon (figure 5). The synoptic situation condition for this day is dominated by a high-pressure system located in the north of Iran that produces easterly light winds in the area.

Occasionally, strong entrainment near the top of the ABL leads to larger temporary growth of the mixed layer making the growth non-uniform with time. This process is often temporal and is considered in the next section.
Region with excess

entrainment

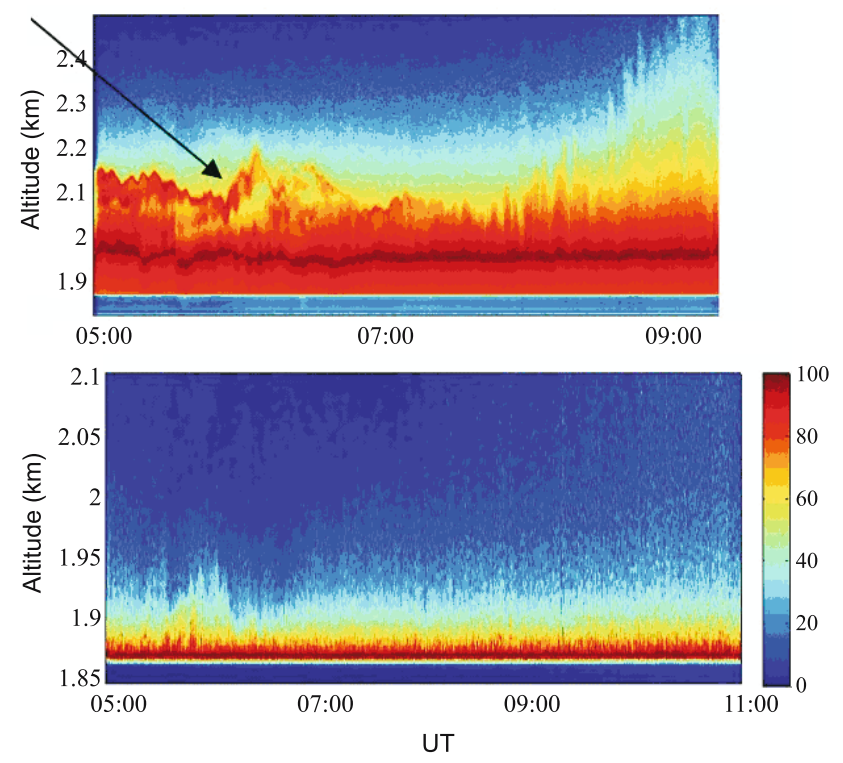

Figure 6. Boundary layer growth from 0500 to 1100 UTC of 12 May 2006. LIDAR uses wavelength of $532 \mathrm{~nm}$ for upper figure and $1064 \mathrm{~nm}$ for lower figure. Using $532 \mathrm{~nm}$ image reveals much more details of the processes in the EZ, hence a temporal enhancement of mixed layer growth has occurred (the color chart is an arbitrary scale unit proportional to backscattered light).

\subsubsection{Entrainment zone}

The mixed layer is usually capped by an entrainment zone (EZ), which provides a transition to the (often stable) lower troposphere (Stull 1988). Entrainment is a result of turbulence driven by the surface heat flux and turbulence generated by wind shear. Thermals, which are positively buoyant at the surface, rise through the mixed layer until they reach the warmer free atmosphere and become negatively buoyant; they overshoot a small distance because of strong static stability in EZ and fall back towards the mixed layer. Strong wind shear in the EZ can lead to instability and turbulence if Richardson number becomes smaller than 0.25.

In these observations we see that the EZ is occasionally accompanied with large entrainment mixing. For example, figure 6 shows two LIDAR backscatter images (for 532 and $1064 \mathrm{~nm}$ respectively) from the entrainment zone that may be associated with breaking Kelvin-Helmholtz instability which is visible to some extent between 05 and 07 UTC, especially in $532 \mathrm{~nm}$ image. Kelvin-Helmholtz (KH) waves are not observed (as usually seen at the top of stable atmospheric boundary layer, e.g., Newsom and Banta 2003) but $\mathrm{KH}$ instability can lead to entrainment of blobs of air with low level aerosol concentrations from the free atmosphere into the top of the boundary 


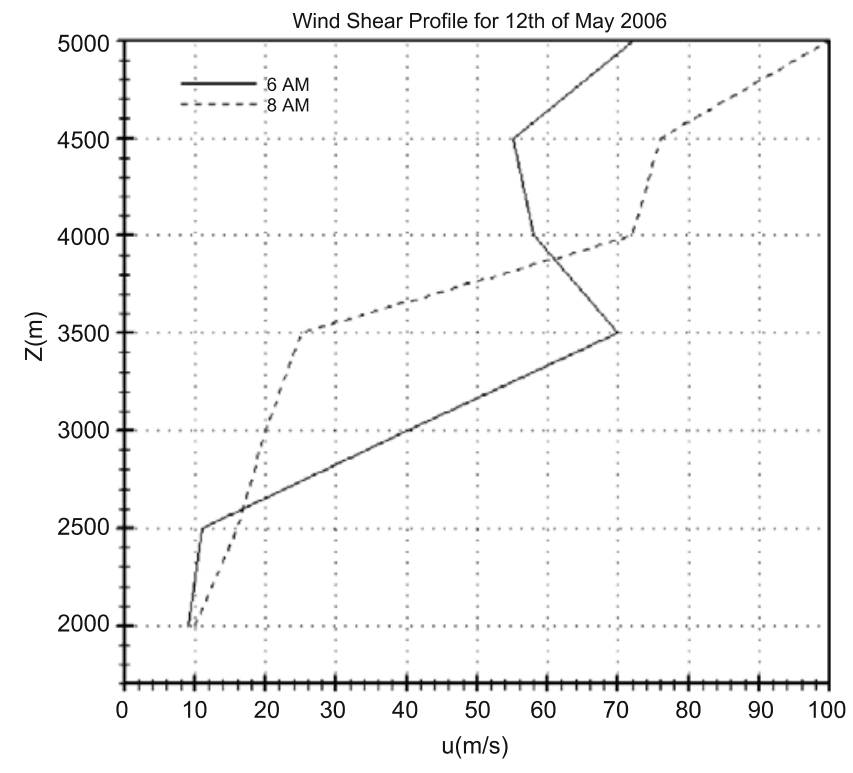

Figure 7. Large wind shear above the mixed layer at 0600 and 0800 UTC on 12 May 2006 (output of MM5).

layer which appear as packets of low backscatter regions as seen in figure 6 . In this period, there is a stronger wind shear in the free atmosphere just above the boundary layer (see figure 7 ), which may cause more mixed layer growth in this period due to shear instability and consequent mixing. Entrainment processes are complicated and are often associated with shear, convection and internal waves breaking (McGarth et al 1997; Bidokhti and Khoshsima 2006).

Fedorovich and Conzemius (2008) have given a good review on the effect of shear on entrainment in ML indicating that the shear production of turbulent kinetic energy (TKE, with a maximum fraction of 0.5 for shear) for entrainment in this zone is much more important than the shear production of TKE near the surface which is mainly balanced by dissipation.

Interaction of internal waves with turbulence in a stratified flow with or without shear has also shown to generate time varying buoyancy flux which in certain moments may become negative (counter gradient processes) as have been observed in grid generated turbulence in a stratified environment (e.g., Itsweire et al 1986; Bidokhti and Britter 2002). Regular variation of entrainment rate at the interface should indicate that the buoyancy flux should also vary. Stronger entertainment should coincide with larger buoyancy flux. Careful field measurements of flux in the entrainment zone may reveal such changes that are worth performing.

\subsection{Numerical experiments}

In order to look at the evolution of mixed layer to compare our LIDAR observations with, we use a mesoscale model to reproduce boundary layer height evolution in this urban area. We use MM5 (http://www.mmm.ucar.edu/mm5) forecasting model for this study in which three domains, two-way nested, are defined using 27 , 9 and $3 \mathrm{~km}$ resolutions. The smallest domain is centered at the LIDAR position. The initial and boundary conditions are updated every $3 \mathrm{~h}$ with model results obtained from the University Corporation for Atmospheric Research (UCAR) model. The model is run without any data assimilations. The initial fields and time-varying boundary variables and sea surface temperatures were taken from the National Centers for Environmental Prediction (NCEP) as FNL one-degree dataset (FNL is a final global data assimilation system). In the vertical, we have used 23 sigma levels, with higher resolution in the atmospheric boundary layer.

In figure 8 , the surface pressure at 12 UTC of 10 July 2006 that was provided by the Iranian Meteorological Service (right) and the one obtained from the model with the medium range forecast (MRF) parameterization in an expanded domain (left), are shown. As can be observed, the model reproduces the synoptic condition quite well. Sensitivity analysis of MM5 to meteorological parameters for Tehran shows that MM5 has a good performance for most parameters in boundary layer but it slightly underestimates the boundary layer temperature, and also gives wetter predictions than observations. Correlation coefficient is nearly $95 \%$ between model results and radiosound observations especially in summer (Ahmadi Givi and Sabetghadam 2006).

In this model we also use simple-ice for the explicit moisture scheme, cloud radiation for the radiation scheme, and Betts and Miller (B-M) scheme for the cumulus parameterization and boundary layer processes are calculated using the MRF scheme. This is a non-local, first-order closure PBL scheme based on the work of Troen and Mahrt (1986) and developed by Hong and Pan (1996), as it is implemented in the Medium-Range Forecast Model of the National Centers of Environmental Program. It consists of two regimes: a stable one and a free convection regime. The free convection regime takes into account the contributions from large-scale eddies in the local; the vertical mixingprocess throughout the whole PBL in this way affects the entrainment at the top of the boundary layer. In this scheme the turbulent fluxes are calculated as a function of friction velocity, convective velocity and height of the mixing layer. The MRF parameterization uses a modified scheme to calculate the boundary layer depth from the Richardson number.

The model is set up for 3 days: 10 May 2006 in spring and 17 and 25 August 2006 in summer 


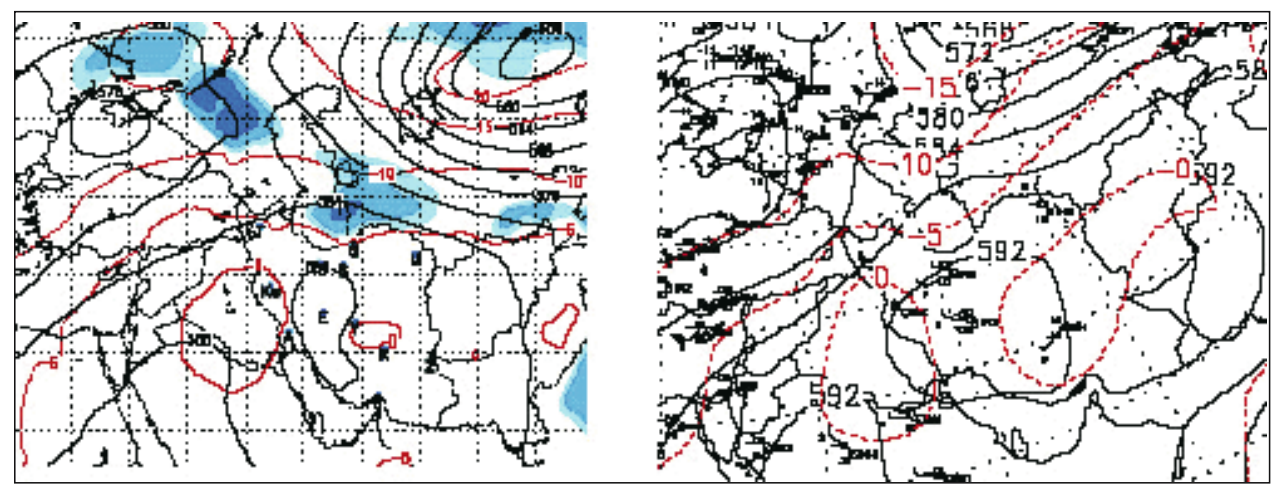

Figure 8. 950-hPa geopotential height at 12 UTC on 10 July 2006. The data are provided by the Iranian Meteorological Service (right), and by the model result (left).

for $24 \mathrm{~h}$ in a day and every $2 \mathrm{~h}$ the outputs were taken for analysis. The boundary layer depth is estimated from the vertical profiles of potential temperature, then the result of the model (for mixed layer height) can be shown in a rather continuous diagram for $24 \mathrm{~h}$.

A variety of methods have been proposed for diagnosing the height of the atmospheric boundary layer based on the vertical potential temperature structure. Holzworth (1967) calculated maximum mixed layer height from the morning temperature soundings and maximum afternoon surface temperature, assuming a dry-adiabatic lapse rate (a method often used in air quality modeling studies) or the top of a constant potential temperature layer (Wetzel 1982). Stull (1988) has defined mixed layer depth as the depth of the layer in which the profiles of potential temperature and specific humidity are constant (having constant mean potential temperature and mean specific humidity throughout the layer) and we used this definition to calculate boundary layer height. With the results of MM5 model we can present continuous profiles of potential temperature for the boundary layer, from which we derive the mixed layer height. Typical error for estimating $z_{i}$ is about $15 \%$, which may be larger when the mixed layer is at its early stage of growth (early mornings).

Figure 9 shows the boundary layer depth during 25 August 2006 as observed by the LIDAR and that estimated from the model. It shows that the model simulates the maximum depth of the boundary layer one hour earlier than that is indicated by observations. However, there is a good consistency between the observations and the model results of MM5; and the delay can possibly be explained by the diffusion of haze near the surface, with the horizontal diffusion speed being faster than the convection of boundary layer in early morning.

Figure 10 shows the time evolution of the surface heat flux, which is estimated by the model for the same days. At about between 12:00 and 14:00 it

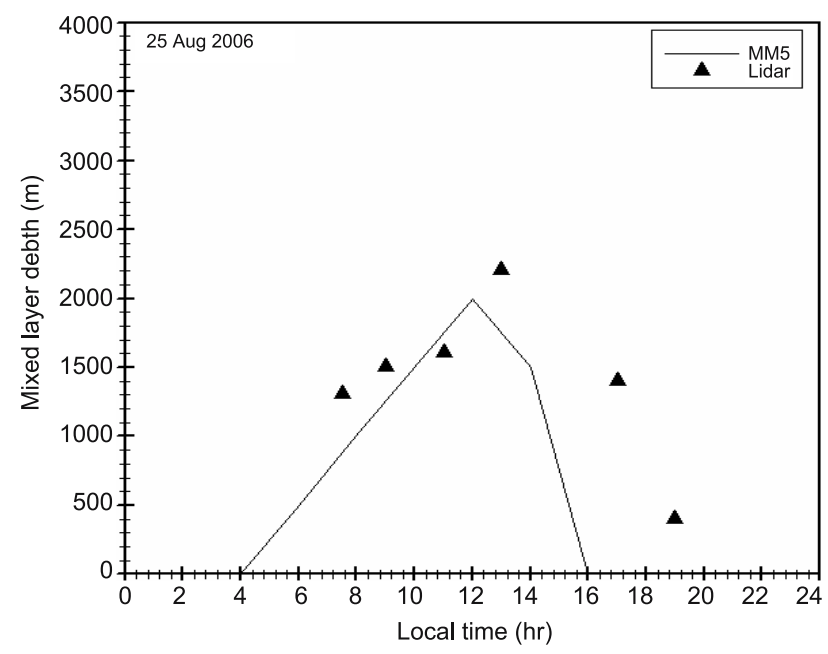

Figure 9. Boundary layer depth during 25 August 2006 (local time) observed by the LIDAR (triangle), and predicted by the MM5 model (solid line).

appears to reach its maximum value, however it has about one-hour delay to the maximum of observed boundary layer height. This delay can be due to the time of formation and evolution of plumes in the convective boundary layer, which are usually averaged out in the model.

Predicted values of $z_{i}$ from the model and observed measurements during 10 May 2006 are compared in figure 11. According to this figure, there is a two-hour delay between the model predictions and the LIDAR estimates of maximum height, but there is a good consistency between the two trends. However, considering the location of Zanjan in the leeward of the Alborz Mountain, the airflow in the boundary layer may be affected by katabatic and anabatic winds in daily cycle during the less active synoptic periods. The horizontal advection due to these winds may influence the development and growth of boundary layer that may not be considered in the model. This may also influence the afternoon decay of the mixed 


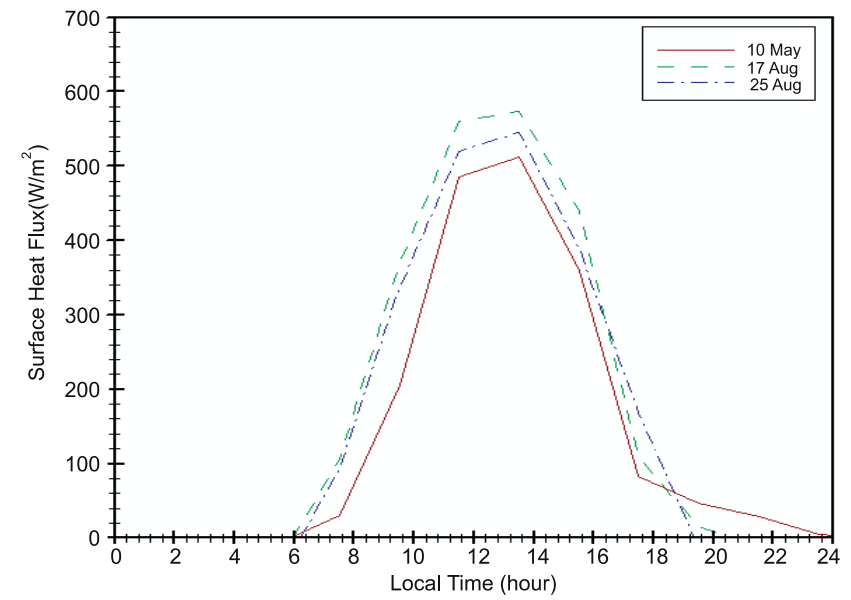

Figure 10. Surface heat flux during 10 May (solid line), 17 August (dashed line) and 25 August (dash-dot line) estimated from MM5 (local time).

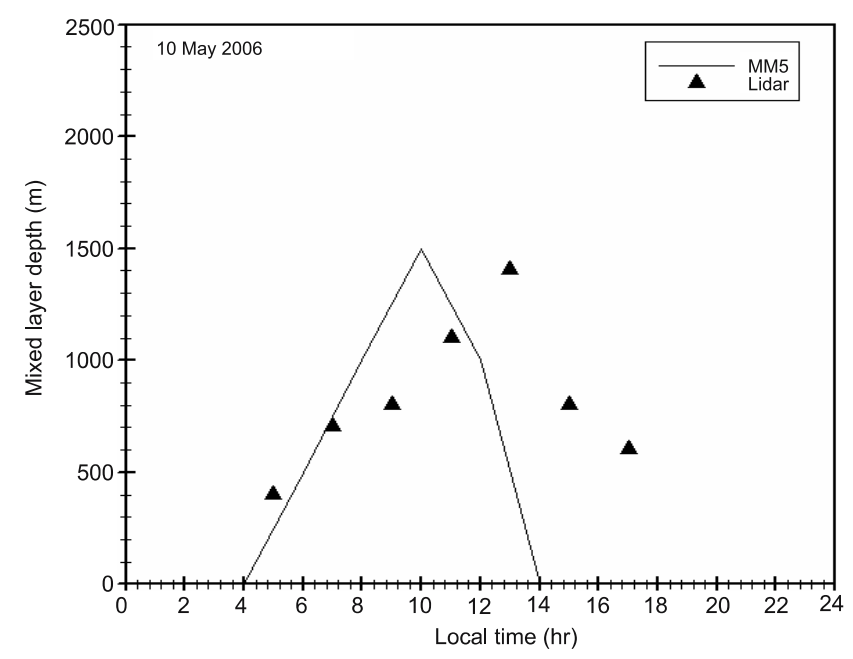

Figure 11. Boundary layer depth during 10 May 2006 (local time) observed by the LIDAR (triangle), and calculated with the MM5 model (solid line).

layer creating discrepancy discussed further below. Hence, further work should be done in order to determine the exact causes of such discrepancy.

The drop in the MLH in the afternoon in the model results appears to be steeper than that of the observations (figure 11). There may be two reasons for this: one can be the result of unevenness of the area which usually create horizontal variations of the mixed layer that is not considered in the model (averaged out); second, as the residual layer above the mixed layer still contains higher level of aerosols in the late afternoon finding, the mean level of the entrainment zone from LIDAR images may give higher value of MLH than that estimated by the model which mainly takes into account the averaged surface forcing (surface heat flux).

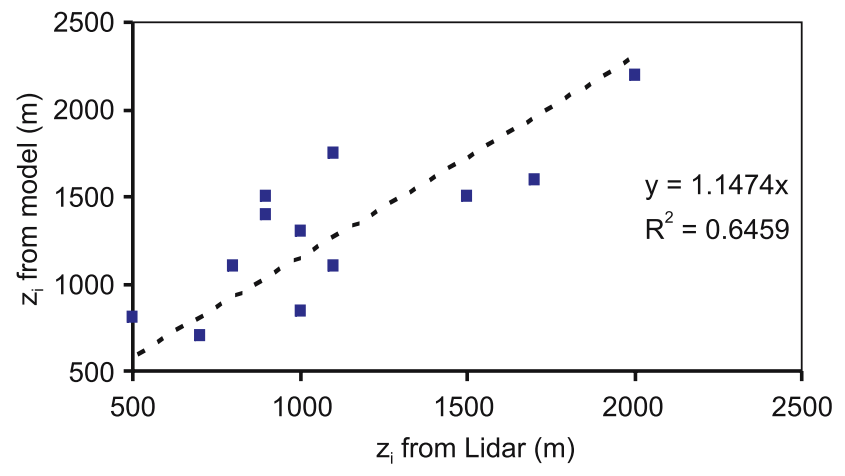

Figure 12. Comparison between the model results and LIDAR observations of MLH for all cases namely: 10 May, 17 and 25 August 2006.

For 17 August 2006 the model simulation gives similar MLH to that of LIDAR observations. The delay, which was observed in previous cases, between the time of maximum mixing height of model result and that of the LIDAR observations, is not substantial, but the model underestimates the mixing height by about $400 \mathrm{~m}$. This may be attributed to the surface heat flux parameterization which may not apply correctly as the land use in the model may require further rectification. Pino and Arellano (2004) have also found similar discrepancy for the Barcelona area in July 2000. A comparison between the observed daytime mixed layer height and that predicted by the model indicates a good consistency especially in summer. An example of such a comparison between the model result and LIDAR observations was done for a few cases and is shown in figure 12. Apart from scatter, there is a good consistency between the two. In the morning, when the layer is shallow because of the increase of aerosol scattering and plume growth, and also in the afternoon, the consistency is less than that of mid-day. Indeed it is because, detecting boundary layer by LIDAR when it is thin is more erroneous than when it is fully developed and thick in which the aerosols are also more mixed and uniformly distributed throughout the boundary layer and this also depends on processes involved in the growth of daytime mixed layer.

The MLH in urban area is particularly coupled with the air pollution concentrations inversely. For example, during early morning when the MLH is shallow there is much less air for being polluted from traffic vehicles in cities, hence large concentrations can occur in the early morning. As MLH increases towards mid-day, the concentration is substantially reduced. Hence, MLH is an important parameter in the prediction of air pollution in large cities as it can be used for example in 'box models' 
directly for calculating mean concentrations (e.g., Hanna 1982).

\section{Conclusions}

A comparative study of daytime mixed layer height using LIDAR observations and a mesoscale numerical model has been carried out in an urban mountainous region in the north of Iran $1700 \mathrm{~m}$ above sea level (Zanjan). The preliminary results indicate a good consistency between the two, but with some discrepancies which include the time of the maximum MLH that occurs sometime earlier than that of observations and decay of the ML in the afternoon which is sharper in the model than that of observation. Such discrepancies are attributed to the complexity of the area that may create nonhomogeneity in the ML that are averaged out in the model. The area is mountainous and lies on the south Alborz Mountain, and on the northern terrain of this mountain lies the Caspian Sea. Hence meteorologically, the area is rather complex and needs extensive study. Surface advection due to local forcing such as the effects of mountains or urbanization may be important in the evolution of the boundary layer in this area and requires further higher resolution numerical modeling with more accurate surface land use.

Estimation of maximum surface heat flux shows that, for spring days, e.g., 10 May, it is smaller than that of summer days namely 17 and 25 August 2006, as expected. Surface heat flux for summer days is not very different; hence similar mixed layer growth is observed for these days. For spring day, smaller surface heat flux and hence smaller $z_{i}$ is observed. Typical mid-day MLH for spring and summer times are found to be typically 1.3 and $2.2 \mathrm{~km}$ with a mean uncertainty of about $15 \%$.

Vertical wind shear above the EZ associated with internal waves appears to have a temporal effect on the rate of growth of the boundary layer height and the LIDAR technique seems to reveal such small scale processes very markedly.

Further numerical modeling and LIDAR observations of the lower atmosphere for different weather conditions in this area with topography are required to understand the way different processes affect the structure of the boundary layer and entrainment zone.

\section{Acknowledgements}

We greatly acknowledge the support of Iranian Meteorological Organization and Mr Abdie of the Institute for Advanced Studies in Basic Sciences (IASBS) of Zanjan for their technical support in this work.

\section{References}

Ahmadi Givi F and Sabetghadam S 2006 Sensitivity Analysis of MM5 Weather Forecasting Model to the choice of the planetary boundary layer scheme for estimating mixed layer depth; Sixth Numerical Weather Prediction Conference, December 2006, Tehran, Iran.

Bidokhti A A and Britter R E 2002 A large stratified shear flow water channel facility; Exp. Fluids 33 281-287.

Bidokhti A A and Khoshsima M 2006 Non-uniform entrainment at a density interface near a continuous stratified fluid in a confined region; Proceedings of the Eleventh Asian Congress of Fluid Mechanics, 22-25 May 2006, Kuala Lumpur, Malaysia.

Boers R E, Eloranta W and Coulter R L 1984 LIDAR observations of mixed layer dynamics: Tests of parameterized entrainment models; J. Climate Appl. Meteor. 23 $247-266$.

Cohn S A and Angevine W M 2000 Boundary-layer height and entrainment zone thickness measured by LIDARs and wind profiling radars; J. Appl. Meteor. 39 1233-1247.

Driedonks A G M and Tennekes H 1984 Entrainment effects in the well-mixed atmospheric boundary layer; Bound. Layer Meteor. 30 75-105.

Fedorovich E and Conzemius R 2008 Effects of wind shear on the atmospheric convective boundary layer structure and evolution; Acta Geophysica 56 114-141.

Flamant C and Flamant P 1997 LIDAR determination of the entrainment zone thickness at the top of the unstable marine atmospheric boundary layer; Bound. Layer Meteor. 83 247-284.

Flamant C and Pelon J 1996 Boundary layer structure over the Mediterranean during Tramontane event; Quart. J. Roy. Meteor. Soc. 122 1741-1778.

Hanna S 1982 A handbook on atmospheric diffusion, US Department of Commerce.

Hogrefe C, Rao S T, Kasibhatla P, Kallos G, Tremback C J and Hao W 2001 Evaluating the performance of regionalscale photochemical modeling systems: Part I. Meteorological predictions; Atmos. Environ. 35 4159-4174.

Holzworth G 1967 Mixing depths, wind speeds and air pollution potential from selected locations in the United States; J. Appl. Met. 6 1039-1044.

Hong S Y and Pan H L 1996 Nonlocal boundary layer vertical diffusion in a medium-range forecast model; Mon. Wea. Rev. 124 2322-2339.

Itsweire E C, Helland K N and Van Atta C W 1986 The evolution of grid-generated turbulence in a stably stratified fluid; J. Fluid Mech. 162 299-338.

Khalesifard H R M, Faridian A, Abdi F and Flamant P H 2004 532-NM Elastic Backscatter LIDAR Station Operated in Northwest Iran for Environmental Studies, In: 22nd International Laser Radar Conference (ILRC 2004); Proceedings of the Conference held 12-16 July, 2004 in Matera, Italy (eds) Gelsomina Pappalardo and Aldo Amodeo, ESA SP-561. Paris: European Space Agency, p. 423.

Kunkel K E, Eloranta W and Shipley S T 1977 LIDAR observations of the convective boundary layer; J. Appl. Meteor. Soc. 16 1306-1311.

Marsik F J, Fischer K W, McDonald T D and Samon P J 1992 Comparison of the methods for estimating mixing height used during the 1992 Atlanta field intensive; J. Appl. Meteor. 34 1802-1814.

Mason P 1989 Large-eddy simulation of the convective atmospheric boundary-layer; J. Atmos. Sci. 46(11) 1492-1516. 
McGarth J I, Fernando H J S and Hunt J C R 1997 Turbulence, waves and mixing near free shear density interfaces, Part 2 Laboratory experiments; J. Fluid Mech. 347 197-234.

Melfi S H, Spinhirne J D, Chou S H and Palm S P 1985 LIDAR observations of vertically organized convection in the planetary boundary layer over the ocean; J. Climate Appl. Meteor. 24 806-821.

Nelson E, Stull R B and Eloranta E W 1989 A prognostic relationship for entrainment zone thickness; J. Appl. Meteor. 28 885-903.

Newsom R K and Banta R M 2003 Shear-Flow Instability in the Stable Nocturnal Boundary Layer as Observed by Doppler Lidar during CASES-99; J. Atmos. Sci. 60 $16-33$.

Pino D and Arellano V 2004 The Boundary Layer Growth in an Urban Area; Science of the Total Environment, 334-335 207-213.
Rocadenbosch F 2003 Lidar-Aerosol Sensing; In: Encyclopedia of Optical Engineering (ed.) Dekker M, 1st edn., New York; 1090-1102.

Seaman N L 2000 Meteorological modeling for air quality assessments; Atmos. Environ. 34 2231-2259.

Stull R B 1988 An introduction to boundary layer meteorology (Dordrecht: Kluwer Academic Publishers).

Stull R B and Eloranta E W 1984 Boundary layer experiment 1983; Bull. Amer. Meteor. Soc. 65 450-456.

Tomasi D and Perrone M 2005 PBL and dust layer evolution by lidar and radiosounding measurement over peninsular site; Atmos. Res. 80(1) 86-103.

Troen I and Mahrt L 1986 A simple model of the atmospheric boundary layer sensitivity to surface evaporation; Bound. Layer Meteor. 43 129-148.

Wetzel P J 1982 Toward parameterization of the stable boundary layer; J. Appl. Met. 21 7-13. 